\title{
Efficacy and safety of plasma exchange for Kawasaki disease with coronary artery dilatation
}

\author{
Yusuke Kaida ${ }^{1 *}$,Takatoshi Kambe1, Shintaro Kishimoto², Yusuke Koteda², Kenji Suda², Ryo Yamamoto', \\ Tetsurou Imai', Takuma Hazama', Yoshimi Takamiya', Ryo Shibata', Hidemi Nishida', Seiya Okuda' \\ and Kei Fukami ${ }^{1}$
}

\begin{abstract}
Background: The treatment of Kawasaki disease is controversial when intravenous immunoglobulin therapy fails, although it typically relies on combinations of prednisolone, infliximab, cyclosporine, and plasma exchange therapy. The goal of the treatment is no longer merely to reduce mortality but also to decrease the sequelae of coronary artery lesions, which are the most common and potentially life-threatening complications. Recently, plasma exchange therapy has been used to treat intravenous immunoglobulin-unresponsive Kawasaki disease with coronary artery lesions. When performed before coronary artery dilatation, the outcomes for plasma exchange are known to be excellent; however, when dilatation is already present, sequelae persist.
\end{abstract}

Methods: Between December 2006 and April 2015, we treated ten patients with Kawasaki disease complicated by coronary artery lesions that received plasma exchange because intravenous immunoglobulin therapy had proven to be ineffective. Here, we retrospectively review the efficacy and safety of plasma exchange therapy in such unresponsive cases against coronary artery lesions in patients with Kawasaki disease when plasma exchange performed after coronary artery dilatation.

Results: In nine of the ten patients (90.0\%), the body temperature was confirmed to be $<37.5^{\circ} \mathrm{C}$ at an average of $2.7 \pm 1$. 4 days after starting plasma exchange. Serum C-reactive protein levels decreased significantly from $9.9 \pm 4.9 \mathrm{mg} / \mathrm{dL}$ before exchange to $1.9 \pm 2.9 \mathrm{mg} / \mathrm{dL}$ after exchange $(P<0.05)$. One year after plasma exchange treatment, the coronary artery lesions had regressed to within normal limits in six of the ten patients. Although lesions remained in three patients, all three of these patients were asymptomatic. In addition, there were no stenosis of the coronary artery in nine of the ten patients. One patient died due to a ruptured giant coronary aneurysm 1 day after starting plasma exchange.

Conclusions: In conclusion, plasma exchange may be effective in not only regressing coronary artery lesions but also preventing sequelae in patients with Kawasaki disease when plasma exchange is performed after coronary artery dilatation.

Keywords: Kawasaki disease, Plasma exchange, Coronary artery

\section{Background}

Kawasaki disease, first reported in 1967, is an acute systemic vasculitis of unknown etiology that predominantly occurs in infants and young children [1]. It is characterized by prolonged fever, rash, bilateral bulbar conjunctival injection, oral mucosal erythema, cervical lymphadenopathy, and hand and foot swelling. Clinically, the course of

\footnotetext{
* Correspondence: kaida_yuusuke@kurume-u.ac.jp

${ }^{1}$ Division of Nephrology, Department of Medicine, Kurume University School

of Medicine, 67 Asahi-machi, Kurume, Fukuoka 830-0011, Japan

Full list of author information is available at the end of the article
}

Kawasaki disease is usually self-limiting, and most patients recover without any long-term sequelae. However, some patients develop complications, of which the most common and potentially life-threatening are cardiovascular manifestations. These cardiovascular manifestations include pericardial, myocardial, endocardial, and coronary artery lesions, such as dilation, aneurysm, and stenosis.

The current goal of Kawasaki disease treatment is no longer merely to reduce the death rate but also to decrease the coronary sequelae. To this end, early treatment with intravenous immunoglobulin (IVIG) is the 
standard initial treatment. However, $15.8 \%$ of cases are unresponsive to IVIG, and $38.5 \%$ of them develop coronary artery abnormalities [2]. Patients with IVIGunresponsive Kawasaki disease are currently treated with prednisolone, infliximab, and cyclosporine and plasma exchange therapy [3-6]. However, no optimal therapeutic regimen has yet been established.

Recent studies have reported the use of plasma exchange therapy in the treatment of IVIG-unresponsive Kawasaki disease [6-8]. When plasma exchange was initiated before the beginning of coronary artery dilatation, no sequelae developed in patients; however, when dilatation had already begun, sequelae developed in $30 \%$ of patients despite the plasma exchange [7]. Hokosaki et al. also reported that treatment outcomes tended to be better when plasma exchange was initiated before day 9 of the disease onset [7]. In this study, we retrospectively reviewed the efficacy and safety of plasma exchange against coronary artery lesions in patients with Kawasaki disease unresponsive to IVIG therapy when coronary artery dilatation had already started.

\section{Methods}

We retrospectively reviewed the clinical records of children with coronary artery lesions caused by Kawasaki disease that had been treated with plasma exchange after IVIG had been proven ineffective. Data from the Kurume University Hospital, for the period between December 2006 and April 2015 , were used. IVIG responsiveness was defined as the resolution of fever (body temperature below $37.5^{\circ} \mathrm{C}$ ) within $24 \mathrm{~h}$ of initiating the IVIG treatment. Usually, plasma exchange is performed at least three times in patients with Kawasaki disease. However, if the high fever is not improved, additional plasma exchange might be performed. When the resolution of fever (body temperature below $37.5{ }^{\circ} \mathrm{C}$ ) was observed, plasma exchange is discontinued. The study protocol was approved by the Institutional Ethics Committees of Kurume University School of Medicine (No16219).

\section{Plasma exchange}

Plasma exchange was generally conducted as a vein-tovein procedure, although an artery-to-vein option was also used until 2006 [7]. For the procedure, a 6- or 7-Fr double-lumen catheter was inserted into the femoral vein. The replacement fluid contained 5\% albumin or fresh frozen plasma, and the amount exchanged was approximately 1.0 - to 1.5 -fold the circulating blood plasma volume $(\mathrm{mL})$, which was calculated as $1 / 13$ body weight $\times[100-$ hematocrit (\%) $]$. An anticoagulant, heparin, was used at an appropriate dose to keep the activated clotting time in the range of 150 to $200 \mathrm{~s}$. While this was being done, sedation was given as needed, and the patient was carefully secured to the bed to avoid movement.

\section{Coronary artery evaluation}

Echocardiography was used to evaluate both cardiac function and the coronary arteries. Dilatation of a coronary artery was diagnosed if the diameter of any artery was $\geq 3 \mathrm{~mm}$ in children younger than 5 years, $\geq 4 \mathrm{~mm}$ in children older than 5 years, or if the coronary artery size was 1.5 times that of neighboring coronary arteries. We diagnosed a coronary aneurysm if the artery diameter was $\geq 4 \mathrm{~mm}$, and we diagnosed a giant coronary aneurysm if it was $\geq 8 \mathrm{~mm}$ [9].

\section{Statistical analysis}

Data are presented as mean \pm standard deviations. Continuous variables were compared using a paired $t$ test. All statistical analyses were performed using GraphPad Prism 5 software (GraphPad Software, Inc., La Jolla, CA, USA).

\section{Results}

\section{Patient characteristics}

We identified ten children with Kawasaki disease (eight boys and two girls) that met the inclusion criteria. The mean age at onset was $23.8 \pm 20.8$ months (range, 363 months), and the mean body weight was $10.8 \pm 4.0 \mathrm{~kg}$ (range, 4.5-17.8 kg). The initial treatment was started after an average of $6.1 \pm 5.3$ days from disease onset. Typically, acetylsalicylic acid, prednisolone, or both were given as part of the initial treatment with IVIG (Table 1). Additional IVIG treatment was performed in five patients (Table 1). Case 10 was treated with infliximab $(5 \mathrm{mg} / \mathrm{kg}) 1$ day after plasma exchange due to elevated CRP levels.

\section{Efficacy of plasma exchange}

On average, plasma exchange was started $13.7 \pm 5.7$ days after onset and was given for $10.2 \pm 4.7 \mathrm{~h}$ per treatment over $3.1 \pm 0.9$ days. The detail of the plasma exchange therapy is shown in Tables 2 and 3. In nine of the ten patients $(90.0 \%)$, the body temperature was confirmed to be $<37.5{ }^{\circ} \mathrm{C}$ at an average of $2.7 \pm 1.4$ days after starting plasma exchange. Serum C-reactive protein levels decreased significantly from $9.9 \pm 4.9 \mathrm{mg} / \mathrm{dL}$ before exchange to $1.9 \pm 2.9 \mathrm{mg} / \mathrm{dL}$ after exchange $(P<0.05)$ (Fig. 1).

Table 4 shows the clinical courses of the coronary artery lesions identified in the patients from before plasma exchange. Coronary artery dilatations were seen in four cases, and aneurysms, in six. One year after plasma exchange treatment, the coronary artery lesions had regressed to within normal limits in six of the ten patients. However, lesions remained in three patients $(1,3$, and 10). Right coronary artery lesions were present in patient $1(4.2 \mathrm{~mm})$ and patient $3(4.6 \mathrm{~mm}) 7$ years after plasma exchange, although these had regressed (Fig. 2). Patient 10 still had lesions of the right coronary 
Table 1 Characteristics of patients

\begin{tabular}{|c|c|c|c|c|c|c|c|c|}
\hline Patient & Gender & Age (months) & BW (kg) & Start of IVIG (day) & Treatment before PE & Dose of IVIG & $\begin{array}{l}\text { Period of } \\
\text { PSL (day) }\end{array}$ & $\begin{array}{l}\text { Additional treatment } \\
\text { of IVIG }\end{array}$ \\
\hline 1 & M & 7 & 7.5 & 6 & ASA, PSL, IVIG $\times 3$ & $\begin{array}{l}1 \mathrm{~g} / \mathrm{kg} \times 2 \\
2 \mathrm{~g} / \mathrm{kg} \times 1\end{array}$ & $11-30$ & - \\
\hline 2 & M & 29 & 13.8 & 4 & ASA, PSL, IVIG $\times 2$ & $2 \mathrm{~g} / \mathrm{kg} \times 2$ & 7.11 & - \\
\hline 3 & M & 7 & 7.4 & 4 & ASA, PSL, IVIG $\times 2$ & $1 \mathrm{~g} / \mathrm{kg} \times 2$ & $6-8$ & $\begin{array}{l}1 \mathrm{~g} / \mathrm{kg} \times 2(\text { days } 9 \text { and } 10), \\
2 \mathrm{~g} / \mathrm{kg} \times 2(\text { day } 11)\end{array}$ \\
\hline 4 & M & 11 & 8.0 & 4 & ASA, IVIG $\times 2$ & $2 \mathrm{~g} / \mathrm{kg} \times 2$ & - & - \\
\hline 5 & $\mathrm{~F}$ & 3 & 4.5 & 5 & ASA, IVIG $\times 2$ & $2 \mathrm{~g} / \mathrm{kg} \times 2$ & $14-59$ & $\begin{array}{l}2 \mathrm{~g} / \mathrm{kg} \times 2 \text { (days } 14 \\
\text { and } 18 \text { ) }\end{array}$ \\
\hline 6 & M & 36 & 13.3 & 4 & ASA, PSL, IVIG $\times 2$ & $2 \mathrm{~g} / \mathrm{kg} \times 2$ & 7,8 & $2 \mathrm{~g} / \mathrm{kg} \times 2$ (day 13) \\
\hline 7 & M & 53 & 14.0 & 4 & ASA, PSL, IVIG $\times 3$ & $\begin{array}{l}1 \mathrm{~g} / \mathrm{kg} \times 2, \\
2 \mathrm{~g} / \mathrm{kg} \times 1\end{array}$ & $6-8$ & - \\
\hline 8 & M & 17 & 10.2 & 4 & PSL, IVIG $\times 2$ & $2 \mathrm{~g} / \mathrm{kg} \times 2$ & $6-27$ & $2 \mathrm{~g} / \mathrm{kg} \times 2($ day 14$)$ \\
\hline 9 & $\mathrm{~F}$ & 12 & 11.9 & 21 & ASA, PSL, IVIG $\times 1$ & $1 \mathrm{~g} / \mathrm{kg} \times 1$ & $4,10,11,14$ & - \\
\hline 10 & M & 63 & 17.8 & 5 & ASA, PSL, IVIG × 3 & $2 \mathrm{~g} / \mathrm{kg} \times 3$ & $6,8,9$ & $\begin{array}{l}2 \mathrm{~g} / \mathrm{kg} \times 2 \text { (days } 10 \\
\text { and } 20 \text { ) }\end{array}$ \\
\hline
\end{tabular}

$B W$ body weight, $A S A$ acetylsalicylic acid, PSL prednisolone, IVIG intravenous immunoglobulin infusion, $P E$ plasma exchange Dose of IVIG: single dose $x$ day

$(6.7 \mathrm{~mm})$ and left anterior descending $(5.1 \mathrm{~mm})$ arteries 1.5 years after plasma exchange. All three of these patients were asymptomatic. In addition, there were no stenosis of the coronary artery in nine of the ten patients. One patient (patient 9) died due to a ruptured giant coronary aneurysm 1 day after starting plasma exchange.

\section{Adverse events}

Sedation was given to all patients, but three required mechanical ventilation and one developed respiratory syncytial virus infection, which improved within a few days. No hemorrhage or infection was observed during plasma exchange. However, decreased blood pressure was often noted after initiating therapy, and two cases required vasopressor support. In both cases, the patients

Table 2 Technical characteristics of plasma exchange therapy 1

\begin{tabular}{lllll}
\hline Patient & Vascular access & $\begin{array}{l}\text { Start of } \\
\text { PE (day) }\end{array}$ & $\begin{array}{l}\text { Duration } \\
\text { for PE (days) }\end{array}$ & $\begin{array}{l}\text { Total operation } \\
\text { time of PE (h) }\end{array}$ \\
\hline 1 & A-V & 3 & 19.5 \\
2 & 7-Fr catheter (FV) & 12 & 3 & 13.0 \\
3 & 6-Fr catheter (FV) & 9 & 4 & 15.0 \\
4 & 8-Fr catheter (FV) & 13 & 3 & 5.0 \\
5 & 6-Fr catheter (FV) & 11 & 3 & 8.0 \\
6 & 6-Fr catheter (FV) & 10 & 4 & 11.5 \\
7 & 6-Fr catheter (FV) & 12 & 3 & 8.0 \\
8 & 6-Fr catheter (FV) & 11 & 4 & 10.0 \\
9 & 6-Fr catheter (FV) & 21 & 1 & 4.5 \\
10 & 8-Fr catheter (FV) & 10 & 3 & 7.5 \\
\hline A V artery & - to-vein, FV femora vein, PE plasma exchange & \\
\hline
\end{tabular}

$A-V$ artery-to-vein, $F V$ femoral vein, $P E$ plasma exchange were in a condition to allow the therapy to continue. Generally, plasma exchange could be safely implemented without causing any life-threatening or irreversible complications.

\section{Discussion}

The present study supports the possibility that outcomes are favorable in cases where plasma exchange is used to treat Kawasaki disease when coronary artery lesions have developed and the course is unresponsive to IVIG therapy. Moreover, we showed that plasma exchange could be safely performed in children with this disease.

Table 3 Technical characteristics of plasma exchange therapy 2

\begin{tabular}{|c|c|c|c|}
\hline Patient & $\begin{array}{l}\text { Total volume of } \\
\text { plasma removed } \\
(\mathrm{mL})\end{array}$ & $\begin{array}{l}\text { Plasma } \\
\text { separator }\end{array}$ & $\begin{array}{l}\text { Replacement } \\
\text { fluid }\end{array}$ \\
\hline 1 & 1415 & Plasma flow OP-05 ${ }^{\circledR}$ & FFP \\
\hline 2 & 5394 & Centrifugation & FFP \\
\hline 3 & 2692 & Centrifugation & FFP \\
\hline 4 & 1540 & Plasma flow OP-02 ${ }^{\circledR}$ & $5 \%$ albumin \\
\hline 5 & 1515 & Plasma flow OP-02 ${ }^{\circledR}$ & $\begin{array}{l}\text { FFP, } 5 \% \\
\text { albumin }\end{array}$ \\
\hline 6 & 3819 & Plasma flow OP-02 ${ }^{\circledR}$ & $\begin{array}{l}\text { FFP, } 5 \% \\
\text { albumin }\end{array}$ \\
\hline 7 & 2800 & Plasma flow OP-02 ${ }^{\circledR}$ & $5 \%$ albumin \\
\hline 8 & 2780 & Plasma flow $\mathrm{OP}-02^{\circledR}$ & $\begin{array}{l}\text { FFP, } 5 \% \\
\text { albumin }\end{array}$ \\
\hline 9 & 600 & Plasma flow OP-02 ${ }^{\circledR}$ & FFP \\
\hline 10 & 3000 & Plasma flow OP-02 ${ }^{\circledR}$ & $5 \%$ albumin \\
\hline
\end{tabular}

FFP fresh frozen plasma 


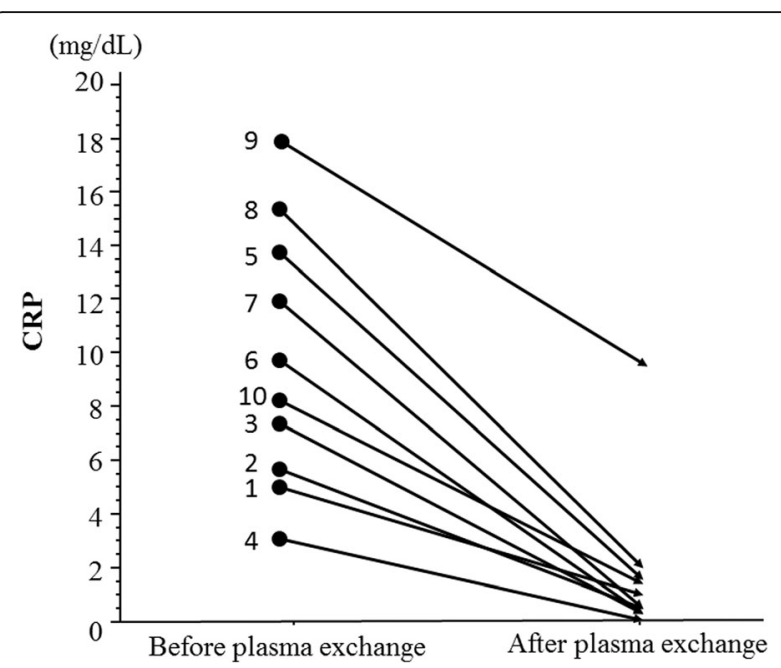

Fig. 1 The serum C-reactive protein (CRP) levels decreased significantly from $9.9 \pm 4.9 \mathrm{mg} / \mathrm{dL}$ to $1.9 \pm 2.9 \mathrm{mg} / \mathrm{dL}(P<0.05)$. PE,

plasma exchange

Recent reports have shown the effectiveness of plasma exchange in patients with IVIG-unresponsive Kawasaki disease $[6,8]$. According to one report, plasma exchange therapy reduced the incidence of coronary artery lesions in Kawasaki disease to < $1 \%$ [8]. Hokosaki et al. described that there were no sequelae when plasma exchange was initiated before the beginning of coronary artery dilatation. However, when dilatation had already begun before the therapy, about $30 \%(6 / 20)$ patients showed persistent sequelae. Further, the size of aneurysms increased in all patients in whom sequelae remained and developed into

Table 4 Patients with coronary artery lesions

\begin{tabular}{|c|c|c|c|}
\hline Patient & $\begin{array}{l}\text { Coronary artery } \\
\text { size before PE } \\
(\mathrm{mm})\end{array}$ & $\begin{array}{l}\text { Coronary artery } \\
\text { size after PE (mm) }\end{array}$ & $\begin{array}{l}\text { Coronary artery } \\
\text { size } 1 \text { year after } \\
\text { treatment }(\mathrm{mm})\end{array}$ \\
\hline 1 & $\begin{array}{l}\text { RCA } 6.9 \text { LMT } 5.0 \\
\text { LAD 4.0 LCx } 3.6\end{array}$ & $\begin{array}{l}\text { RCA } 13.1 \text { LMT } 6.9 \\
\text { LAD 7.0 LCx } 7.0\end{array}$ & RCA 4.9 \\
\hline 2 & RCA 3.3 LAD 4.1 & Regression & Regression \\
\hline 3 & RCA 3.6 LAD 3.4 & RCA 5.0 LAD 5.6 & $\begin{array}{l}\text { RCA } 5.9 \\
\text { LAD } 5.1\end{array}$ \\
\hline 4 & RCA 4.1 LAD 4.9 & RCA 3.4 LAD 4.4 & Regression \\
\hline 5 & RCA 3.1 & Regression & Regression \\
\hline 6 & LMT 4.3 & LMT 4.7 & Regression \\
\hline 7 & RCA 3.1 & RCA 3.0 & Regression \\
\hline 8 & $\begin{array}{l}\text { RCA } 3.0 \text { LMT } 3.2 \\
\text { LAD } 3.0\end{array}$ & $\begin{array}{l}\text { RCA } 4.4 \text { LMT } 3.5 \\
\text { LAD } 5.0\end{array}$ & Regression \\
\hline 9 & $\begin{array}{l}\text { RCA } 15.1 \text { LMT } 3.5 \\
\text { LAD } 18.2\end{array}$ & $\begin{array}{l}\text { Death due to } \\
\text { ruptured coronary } \\
\text { artery aneurysm }\end{array}$ & - \\
\hline 10 & $\begin{array}{l}\text { RCA } 4.3 \text { LMT } 3.5 \\
\text { LAD } 4.5\end{array}$ & RCA 6.6 LAD 7.5 & $\begin{array}{l}\text { RCA } 5.5 \\
\text { LAD } 6.0\end{array}$ \\
\hline
\end{tabular}

$L C X$ left circumflex, $L A D$ left descending artery, $L M T$ left main trunk, $R C A$ right coronary artery giant aneurysms in five of the six patients in the late period ( $\geqq 1$ year after onset) [7]. However, despite starting plasma exchange after the beginning of coronary artery expansion, we demonstrated that plasma exchange could improve the size of coronary artery lesions in almost all of the patients. For example, after plasma exchange, coronary artery lesions regressed to within normal limits in six of the ten patients and improved in another two patients. This is consistent with a previous case report that plasma exchange therapy significantly improved coronary artery lesions [10]. Furthermore, the aneurysms did not develop into giant aneurysms even in more than 1 year after onset in all of our patients. The period of until the start of the plasma exchange after onset was $13.7 \pm 5.7$ days in our study, whereas $8.1 \pm 1.9$ days reported by Hokosaki et al. [7]. Though plasma exchange was started late, coronary artery lesions regressed in almost all of our patients. In addition, there were no stenosis of the coronary artery. Therefore, plasma exchange may be effective not only in treating coronary artery lesions but also in preventing sequelae in patients with IVIG-unresponsive disease when plasma exchange performed after coronary artery dilatation.

In this study, one patient died due to a ruptured giant coronary aneurysm (patient 9), and another patient showed progression to a giant aneurysm (patient 1). In Japan, approximately $0.3-0.4 \%$ of patients are reported to develop giant coronary aneurysms $[11,12]$, and their formation is one of the most important factors affecting the prognosis of Kawasaki disease. Giant coronary aneurysms pose the greatest risk of thrombosis and stenosis (myocardial infarction). However, there is only a slight risk of rupture, and the incidence of rupture as a cause of death is very low compared with either myocardial infarction or myocarditis. There have been very few reports of ruptures of giant coronary aneurysms due to Kawasaki disease, although whenever reported, these were fatal [13]. Unfortunately, patient 9 died owing to a ruptured giant coronary aneurysm. Although plasma exchange basically should be indicated to IVIG-resistant patients, this patient had received IVIG and plasma exchange on the same day. Unstable circulation and anticoagulant associated with plasma exchange might influence the rupture of the aneurysm. In addition, it has been reported that the use of corticosteroids in the acute phase of Kawasaki disease for patients with evolving coronary artery aneurysms might be associated with worsening involvement and impaired vascular remodeling [14]. Therefore, plasma exchange and the use of corticosteroids may have serious concerns in some situation.

Recently, the age less than 1 year has been reported to be a significant risk factor for giant coronary aneurysms $[15,16]$, with increased likelihoods also associated with age more than 5 years, especially in males [16]. In the 


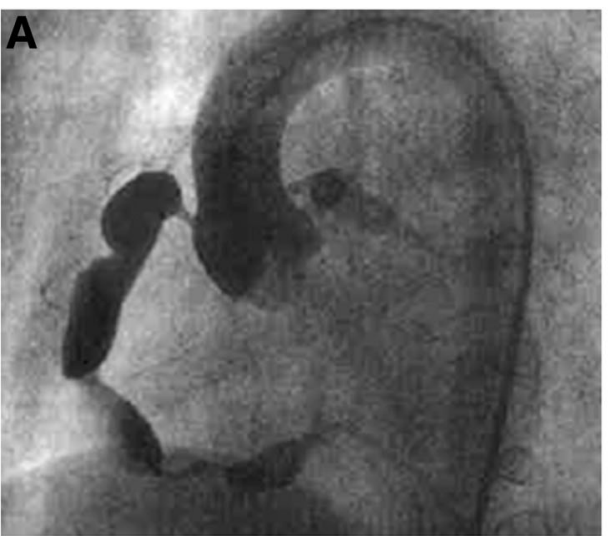

1 month after plasma exchange

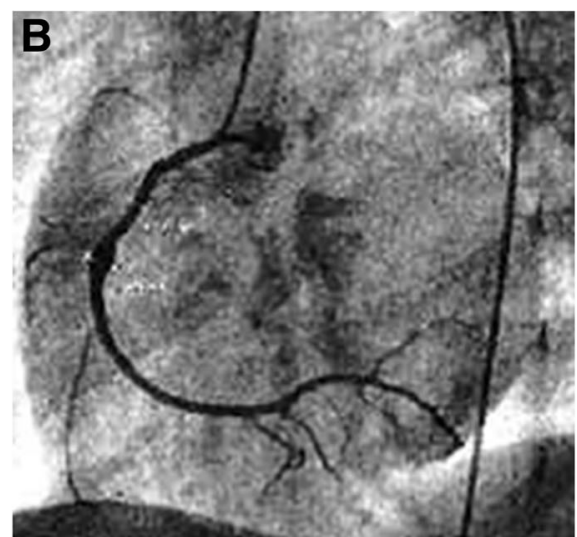

5 years after plasma exchange

Fig. 2 Representative coronary angiography in patient 1. Coronary angiography in the right coronary artery 1 month (a) and 5 years (b) after plasma exchange in patient 1

present study, two cases of giant coronary aneurysms occurred in patients younger than 1 year. In addition, patient 3 was male and younger than 1 year, while patient 10 was older than 5 years and male. Therefore, both age and sex appear to be important for the management of Kawasaki disease and should be considered when stratifying the risk of developing coronary aneurysms.

When plasma exchange was started before coronary artery dilatation began, there were no sequelae [7]. Hokosaki et al. also found that the outcome of plasma exchange was better when plasma exchange started before day 9 after onset [7]. In the present study, two cases of giant coronary aneurysms were treated after more than 20 days had passed since the disease onset. These results are compatible with the view that plasma exchange should be started as early as possible, before coronary artery dilatation has started.

The pathogenesis of coronary artery aneurysm formation in Kawasaki disease remains unknown. It has been reported that elevations in proinflammatory cytokines, such as interleukin (IL)-6, tumor necrosis factor (TNF)$\alpha$, and IL- $1 \beta$, are closely related to the pathogenesis of Kawasaki disease [17-19]. Fujimura et al. reported that IL-6, TNF- $\alpha$ (including TNF receptors 1 and 2), granulocyte colony-stimulating factor, and IL-17 were significantly decreased after plasma exchange treatment [20]. In particular, TNF- $\alpha$ has been shown to be necessary for the development of coronary artery lesions in Kawasaki disease [21]. Although we did not measure TNF- $\alpha$ in these patients, we did show that serum C-reactive protein levels and fever both improved rapidly after the initiation of plasma exchange treatment. Therefore, we speculate that the effect of plasma exchange might be related to the removal of these cytokines.

Adverse effects associated with plasma exchange, such as hypotension, bleeding, allergy, and infection, have been reported [22]. Although complications occurred in some patients, they were treatable and plasma exchange could be continued. Moreover, there were no deaths attributable to plasma exchange therapy. These findings indicate that plasma exchange is a safe treatment modality in children.

These results should, however, be considered in the context of the study's limitations. Notably, it had a small sample size and was not performed as a controlled clinical trial. We also did not compare plasma exchange with other therapies like infliximab, and the initial IVIG doses and timings may have differed from those used in other hospitals. A further clinical study that takes these issues into account might be needed.

\section{Conclusions}

In conclusion, plasma exchange may be effective in not only regressing coronary artery lesions but also preventing sequelae in patients with IVIG-unresponsive disease when plasma exchange is performed after coronary artery dilatation.

In addition, although plasma exchange generally appears to be safe, this study, in conjunction with other reports, indicates that outcomes are unfavorable if it is started when giant coronary aneurysms are present.

\section{Acknowledgements}

The authors would like to thank Enago (http://www.enago.jp) for the English language review.

\section{Funding}

None.

\section{Availability of data and materials}

The datasets during and/or analyzed during the current study are available from the corresponding author on reasonable request.

\section{Authors' contributions}

YKa, TK, and FK carried out the conception and design, data collection, data analysis, and manuscript writing. KS, YKo, KS, RY, TI, TH, YT, RS, HN, and SA participated in the design and coordination of the manuscript. All authors read and approved the final manuscript. 


\section{Ethics approval and consent to participate}

The study protocol was approved by the Institutional Ethics Committees of Kurume University School of Medicine (No16219).

\section{Consent for publication}

Not applicable.

\section{Competing interests}

The authors declare that they have no competing interests.

\section{Publisher's Note}

Springer Nature remains neutral with regard to jurisdictional claims in published maps and institutional affiliations.

\section{Author details}

'Division of Nephrology, Department of Medicine, Kurume University School of Medicine, 67 Asahi-machi, Kurume, Fukuoka 830-0011, Japan. ²Department of Pediatrics and Child Health, Kurume University School of Medicine, Kurume, Japan. ${ }^{3}$ Clinical Engineering Center, Kurume University Hospital, Kurume, Japan.

Received: 31 January 2017 Accepted: 6 September 2017

Published online: 30 October 2017

\section{References}

1. Kawasaki T. Acute febrile mucocutaneous syndrome with lymphoid involvement with specific desquamation of the fingers and toes in children. Arerugi. 1967;16:178-222.

2. Fukunishi M, Kikkawa M, Hamana K, Onodera T, Matsuzaki K, Matsumoto $Y$, et al. Prediction of non-responsiveness to intravenous high-dose gammaglobulin therapy in patients with Kawasaki disease at onset. J Pediatr. 2000;137:172-6.

3. Kobayashi T, Saji T, Otani T, Takeuchi K, Nakamura T, Arakawa H, et al. Efficacy of immunoglobulin plus prednisolone for prevention of coronary artery abnormalities in severe Kawasaki disease (RAISE study): a randomised, open-label, blinded-endpoints trial. Lancet. 2012;379:1613-20.

4. Burns JC, Mason WH, Hauger SB, Janai H, Bastian JF, Wohrley JD, et al. Infliximab treatment for refractory Kawasaki syndrome. J Pediatr. 2005;146:662-7.

5. Suzuki H, Terai M, Hamada H, Honda T, Suenaga T, Takeuchi T, et al. Cyclosporin A treatment for Kawasaki disease refractory to initial and additional intravenous immunoglobulin. Pediatr Infect Dis J. 2011;30:871-6.

6. Mori M, Imagawa T, Katakura S, Miyamae T, Okuyama K, Ito S, et al. Efficacy of plasma exchange therapy for Kawasaki disease intractable to intravenous gamma-globulin. Mod Rheumatol. 2004;14:43-7.

7. Hokosaki T, Mori M, Nishizawa T, Nakamura T, Imagawa T, Iwamoto M, et al. Long-term efficacy of plasma exchange treatment for refractory Kawasaki disease. Pediatr Int. 2012;54:99-103.

8. Imagawa T, Mori M, Miyamae T, Ito S, Nakamura T, Yasui K, et al. Plasma exchange for refractory Kawasaki disease. Eur J Pediatr. 2004;163:263-4.

9. Masuzawa Y, Mori M, Hara T, Inaba A, Oba MS, Yokota S. Elevated D-dimer level is a risk factor for coronary artery lesions accompanying intravenous immunoglobulin-unresponsive Kawasaki disease. Ther Apher Dial. 2015;19:171-7.

10. Mori M, Tomono N, Yokota S. Coronary arteritis of Kawasaki disease unresponsive to high-dose intravenous gammaglobulin successfully treated with plasmapheresis. Nihon Rinsho Meneki Gakkai Kaishi. 1995;18:282-8.

11. Nakamura Y, Yashiro M, Uehara R, Oki I, Kayaba K, Yanagawa H. Increasing incidence of Kawasaki disease in Japan: nationwide survey. Pediatr Int. 2008;50:287-90.

12. Nakamura $Y$, Yashiro M, Uehara R, Oki I, Watanabe M, Yanagawa $\mathrm{H}$. Epidemiologic features of Kawasaki disease in Japan: results from the nationwide survey in 2005-2006. J Epidemiol. 2008;18:167-72.

13. Imai Y, Sunagawa K, Ayusawa M, Miyashita M, Abe O, Suzuki J, et al. A fatal case of ruptured giant coronary artery aneurysm. Eur J Pediatr. 2006;165:130-3.

14. Millar K, Manlhiot C, Yeung RS, Somji Z, McCrindle BW. Corticosteroid administration for patients with coronary artery aneurysms after Kawasaki disease may be associated with impaired regression. Int J Cardiol. 2012:154:9-13.

15. Sudo D, Monobe Y, Yashiro M, Sadakane A, Uehara R, Nakamura Y. Casecontrol study of giant coronary aneurysms due to Kawasaki disease: the 19th nationwide survey. Pediatr Int. 2010;52:790-4.
16. Nakamura Y, Yashiro M, Uehara R, Watanabe M, Tajimi M, Oki I, et al. Casecontrol study of giant coronary aneurysms due to Kawasaki disease. Pediatr Int. 2003;45:410-3.

17. Matsubara T, Furukawa S, Yabuta K. Serum levels of tumor necrosis factor, interleukin 2 receptor, and interferon-gamma in Kawasaki disease involved coronary-artery lesions. Clin Immunol Immunopathol. 1990;56:29-36.

18. Okada Y, Shinohara M, Kobayashi T, Inoue Y, Tomomasa T, Morikawa A, et al. Effect of corticosteroids in addition to intravenous gamma globulin therapy on serum cytokine levels in the acute phase of Kawasaki disease in children. J Pediatr. 2003;143:363-7.

19. Sohn MH, Noh SY, Chang W, Shin KM, Kim DS. Circulating interleukin 17 is increased in the acute stage of Kawasaki disease. Scand J Rheumatol. 2003:32:364-6.

20. Fujimaru T, Ito S, Masuda H, Oana S, Kamei K, Ishiguro A, et al. Decreased levels of inflammatory cytokines in immunoglobulin-resistant Kawasaki disease after plasma exchange. Cytokine. 2014;70:156-60.

21. Hui-Yuen JS, Duong $\Pi$, Yeung RS. TNF-alpha is necessary for induction of coronary artery inflammation and aneurysm formation in an animal model of Kawasaki disease. J Immunol. 2006;176:6294-301.

22. Shemin D, Briggs D, Greenan M. Complications of therapeutic plasma exchange: a prospective study of 1,727 procedures. J Clin Apher. 2007;22:270-6.

\section{Submit your next manuscript to BioMed Central and we will help you at every step:}

- We accept pre-submission inquiries

- Our selector tool helps you to find the most relevant journal

- We provide round the clock customer support

- Convenient online submission

- Thorough peer review

- Inclusion in PubMed and all major indexing services

- Maximum visibility for your research

Submit your manuscript at www.biomedcentral.com/submit
Biomed Central 